\title{
LOS FANTASMAS EN EL TEATRO DE ITZIAR PASCUAL: MEMORIA Y CONSTRUCCIÓN IDENTITARIA ${ }^{1}$
}

\author{
LUISA GARCÍA-MANSO \\ Universität Passau \\ e-mail: mai.gmanso@gmail.com
}

Recibido: 01-07-2014

Aceptado: 05-11-2014

(c) (1)

\section{RESUMEN}

Este ensayo ofrece un análisis de los personajes fantasmales que aparecen en varias obras de Itziar Pascual (Fuga, El domador de sombras, Blue Mountain, La paz del crepúsculo, Père Lachaise, Despedida, Mascando ortigas y Variaciones sobre Rosa Parks), en las que se observa la estrecha relación que guarda la introducción de espectros con la reivindicación de la memoria y la indagación en la identidad tanto individual como colectiva.

PAlabras clave: teatro, fantasmas, memoria, identidad.

\section{Abstract}

This essay offers an analysis of the phantoms that appear in several plays by Itziar Pascual (Fuga, El domador de sombras, Blue Mountain, La paz del crepúsculo, Père Lachaise, Despedida, Mascando ortigas y Variaciones sobre Rosa Parks). There is a relationship between the presence of these spectral characters in theatre, the recovery of memory and the construction of personal and collective identity.

KEYwORDS: theatre, phantoms, memory, identity.

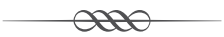

1 Este estudio ha contado con la financiación de una beca de investigación postdoctoral de la Fundación Alexander von Humboldt y se ha realizado en el marco del proyecto de investigación I+D+i Industrias culturales e Igualdad: textos, imágenes, públicos y valoración económica (FFI2012-35390). 
La creación de fantasmas, sombras, muertos vivientes, personajes históricos redivivos y otras proyecciones sobrenaturales de seres irreales y fantásticos no es ajena a las Artes escénicas. Entre los fantasmas y muertos vivientes más célebres del teatro se hallan algunos con tanta fuerza expresiva como el espectro del padre en el Hamlet shakespeariano o la estatua del Comendador de El burlador de Sevilla, de Tirso de Molina. Su papel argumental es fundamental en la trama de las obras, convirtiéndose en ambos casos en artífices y desencadenantes de los dilemas trágicos a los que los protagonistas vivos han de enfrentarse. La creación de atmósferas inquietantes y siniestras, acompañadas de premoniciones de muerte, cuenta también con una amplia tradición dramática, dentro de la cual podemos mencionar obras tan significativas como El caballero de Olmedo, de Lope de Vega, o La intrusa, de Maeterlinck. En estas obras el espacio sonoro y la iluminación, entre otros recursos escénicos y convenciones dramáticas, se utilizan para mostrar lo irreal en escena y crear la ilusión de lo fantástico.

En el teatro español contemporáneo la creación de personajes espectrales sigue siendo un recurso muy utilizado (De Beni, 2012: 153-68). Sin embargo, la presencia de fantasmas responde en muchos casos a una necesidad diferente a la que pudo animar a los autores de las obras previamente citadas a introducir en sus textos figuras extraordinarias. En su análisis sobre el teatro francés contemporáneo, Leila Adham indica que Auschwitz marca un antes y un después en la configuración teatral del espectro, en la medida en que su representación va asociada a la existencia de un pasado que no ha sido superado todavía y regresa para acechar a los vivos. ${ }^{2}$ El mismo fenómeno es observable en otros ámbitos de las representaciones culturales, como la narrativa o el cine. La memoria toma cuerpo a través de peculiares fantasmas que se comunican con los vivos para ayudarles a superar traumas tanto individuales como colectivos.

El carácter espectral de los discursos sobre el pasado fue puesto en evidencia por Jacques Derrida en su ensayo Spectres de Marx (1993), donde crea el neologismo 'hantologie' (de 'hanter'/ 'hantise': aparecerse, perseguir / obsesión) para referirse al estado espectral de la historia, que ni entra en la categoría del ser, ni en la del no-ser. En Disremembering the Dictatorship (2000), vo-

2 «Rencontrer le spectre dans le théâtre contemporain ne renvoie donc pas à une experience métaphysique aux prises avec les forces de l'au-delà comme dans le théâtre d'avant Auschwitz. Rencontrer le spectre, c'est s'inscrire dans l'histoire, et prendre conscience de l'héritage des Anciens. Rencontrer le spectre, c'est comprendre que le passé n'est pas fini, car le passé est un temps qui n'en finit pas de finir, imprimant toujours une nouvelle trace dans le présent. Rencontrer le spectre, c'est donc mesurer le problème posé par l'héritage... d'un passé qui ne passe pas» (Adham, 2008: 477). 
lumen editado por Joan Ramon Resina, se plantea cómo el «pacto de silencio» de la Transición democrática española dio pie a la aparición de un gran número de formas espectrales en el ámbito de las representaciones culturales que reclamaban la consideración de la memoria del franquismo. Jo Labanyi se refiere al carácter espectral de los discursos sobre el pasado adaptando el concepto de 'hantologie' de Derrida a su estudio de la novela y el cine español posfranquista, en los que comienzan a destaparse los velos de la memoria, aunque con una fuerte presencia del trauma (2000). José Colmeiro considera asimismo que la presencia de fantasmas en la literatura española es una consecuencia del trauma histórico y que, mediante ellos, se apela a la necesidad de integrar el pasado en la conciencia colectiva, para poder avanzar hacia el futuro. ${ }^{3}$

En el teatro español contemporáneo, la memoria de episodios traumáticos de la Historia reciente como la Guerra Civil, la dictadura franquista y el exilio republicano de 1939 aparece a menudo encarnada en la voz de personajes venidos del más allá. En algunos casos, estos fantasmas son conocidos personajes históricos, en otros, se trata de seres anónimos que, como describía Unamuno en su definición de la intrahistoria, son la base sobre la que «se alzan los islotes de la Historia» (1972: 28). Entre los fantasmas históricos de la escena contemporánea se halla el del propio Miguel de Unamuno que, en Cantando bajo las balas (2007), de Antonio Álamo, es rememorado por el general Millán Astray, quien sale de su tumba para explicar al público los detalles de lo acontecido el 12 de octubre de 1936, día en que tuvo lugar el primer acto del franquismo en el Paraninfo de la Universidad de Salamanca, donde el escritor de origen vasco pronunció el célebre «venceréis, pero no convenceréis». También sube a las tablas la escritora y feminista riojana María Lejárraga (María Martínez Sierra), quien realiza un repaso sobre los acontecimientos más importantes de su vida a través de sus «fantasmas más dolorosos» (Muro Munilla, 2012: 91) en Y María, tres veces amapola, María... (2002), de Maite Agirre (Nieva-de la Paz, 1999). Sin embargo, se encuentran con mayor frecuencia ejemplos teatrales de fantasmas anónimos, seres que se comunican con los vivos para dar significado a la memoria de un pasado reciente. Así ocurre, por

3 «We can see that Spain's historical trauma is the originating cause of these narratives populated by ghosts. The spectral nature of that past, full of voids, omissions, and disappearances, cannot form a continuous narrative without distortion. Below the smooth surface of official accounts of history, lie those stories that have been silenced and erased, leaving only their ghostly traces, and therefore bound to return and haunt the present. [...] Ghosts, as embodiment of the past in the present, destabilize the accepted notions of history, reality, and self, and the clear demarcations that define them. [...] Ghosts remind us that we need to confront our past if we want to move ahead and construct a better future» (Colmeiro, 2011: 31). 
ejemplo, en La ciudad sitiada (1997), La frontera (2009) y Santa Perpetua (2011), de Laila Ripoll; La tierra (2000) y Para quemar la memoria (2000), de José Ramón Fernández; o Bilbao: Lauaxeta, tiros y besos (2002), de Maite Agirre.

Un primer acercamiento a este grupo de obras nos permite observar la estrecha relación que se establece entre la proliferación de personajes fantasmales en el teatro y el proceso de construcción de las identidades individuales y colectivas. En las obras que tratan temas históricos este aspecto se hace evidente por la influencia que tienen las imágenes, discursos e ideas preconcebidas en torno a la Historia en la evolución de los paradigmas identitarios de la comunidad a la que se dirigen (García-Manso, 2013: 59-61). Sin embargo, también en textos dramáticos recientes que no plantean temas históricos, la función de los personajes fantasmales sigue siendo llevar a los protagonistas de las obras hacia una reconfiguración identitaria. Me refiero a aquellos fantasmas que, como el Espectro-padre de Victor Bevch (2005), de Laila Ripoll, regresan del «más allá» para cuestionar la actitud de los vivos, recordándoles quiénes son y de dónde vienen (García-Manso, 2011: 120). Su función es ayudar a los personajes principales a resolver problemas del presente, lo que comporta necesariamente un proceso de anagnórisis identitaria.

En este ensayo, nos vamos a centrar en los personajes espectrales del teatro de Itziar Pascual (Madrid, 1967), un tema al que la propia autora ha dedicado reflexiones. En su ensayo titulado «Un esbozo de ideario dramático», resaltaba el protagonismo que cobran en su obra los «espectros, fantasmas, sombras, muertos. Seres irreales, enigmáticos, que trascienden los saberes comunes, que subvierten la dicotomía muerte-vida» (2002: 104). Unos años después, en otro ensayo, trata específicamente el tema de los fantasmas en el teatro contemporáneo, realizando un repaso sobre varias obras emblemáticas de autores españoles. ${ }^{5}$ La autora observa las similitudes existentes en el tratamiento que se le otorga a los fantasmas en el teatro reciente: «se han desvestido de solemnidad y trascendencia. Aparecen de manera sencilla, su apariencia no es extravagante ni extraordinaria, su expresión verbal tampoco» (Pascual, 2005b: 152). Asimismo, destaca la relación que estos muertos vivientes mantienen «con la memoria» (155), una relación que, como vamos a analizar, se convierte en el rasgo predominante del fantasma contemporáneo, gra-

4 Sobre los muertos vivientes en la obra de Laila Ripoll, véase Guzmán (2012).

5 Comienza su recorrido por autores clásicos contemporáneos como Valle-Inclán, García Lorca o Casona, pasando a continuación a destacar la obra de autores vivos, algunos de ellos pertenecientes a su misma generación. Finalmente, menciona los títulos de obras propias en las que aparecen fantasmas, que en su opinión tienen «funciones dramatúrgicas idénticas a las de los autores expuestos anteriormente» (Pascual, 2005b: 158). 
cias a la cual su presencia sobre la escena cobra pleno sentido. Además, observaremos cómo influye la reflexión que se realiza en las obras sobre la memoria en la construcción identitaria, una preocupación que se halla muy presente en la totalidad de la obra de Itziar Pascual.

Uno de los primeros textos dramáticos de la autora madrileña en el que encontramos personajes fantasmales es Fuga (1994), una obra situada en un lugar imaginario, la Isla del Sueño, cuyos habitantes padecen las secuelas de una guerra todavía activa. A pesar de que en la acción intervienen personajes extraordinarios, muertos vivientes identificados en el texto como «almas en pena», su localización en un entorno imaginario impide que la obra pueda considerarse fantástica. ${ }^{6}$ De todas formas, su función dramática en relación con la memoria es comparable a la de otros personajes fantasmales creados por Itziar Pascual. Los personajes de Fuga se mueven entre la alegoría y el mito, se expresan a través de monólogos de carácter lírico y aparecen denominados en la mayoría de los casos con nombres comunes, que identifican su función dentro de la sociedad en guerra. El protagonismo de la obra es coral, en el sentido de que no destacan unos personajes sobre otros, sino que todos ellos componen la imagen global de la destrucción de la guerra. Por un lado, nos encontramos con las víctimas pasivas y activas del conflicto bélico (la Harapienta, la Nodriza, el Soldado, el Vigía, etc.) y, por otro, con sus artífices y convencidos defensores (el Señor de Bellver, el General). En una segunda versión de la obra (Pascual, 2005c), se incluyen dos personajes alegóricos, Arrojo y Cautela, cuyos diálogos le aportan un marco narrativo al drama. Son «almas en pena» que se proponen alumbrar el pasado de los habitantes de la Isla del Sueño, erigida en símbolo de tantas sociedades contemporáneas afectadas por la guerra:

CAUTELA: El olvido es tierra yerma. Entre los surcos desgastados queda la verdad escondida. Puede que si alumbramos la memoria de la Isla del sueño, alguien inicie los nuevos tiempos.

[...] ARROJO: Ayúdame a recordar. Yo sola no puedo. Ayúdame.

CAUTELA: Te ayudaré. Tejeremos juntas el sentido de las viejas palabras. (Pascual, 2005c: 2).

6 «La mayoría de los críticos coincide en señalar que la condición indispensable para que se produzca el efecto fantástico es la presencia de un fenómeno sobrenatural. Pero eso no quiere decir que toda la literatura en la que intervenga lo sobrenatural deba ser considerada fantástica. [...] Así, para que la historia narrada sea considerada fantástica, debe crearse un espacio similar al que habita el lector, un espacio que se verá asaltado por un fenómeno que trastornará su estabilidad. Es por eso que lo sobrenatural va a suponer siempre una amenaza para nuestra realidad, que hasta ese momento creíamos gobernada por leyes rigurosas e inmutables» (Roas, 2001: 7-8). 
Arrojo desea «recordar», «alumbrar la memoria» con el fin de iniciar «los nuevos tiempos»y, para ello, desfilarán por el escenario las víctimas y los artífices de la guerra. Junto con otras almas en pena, se nos presenta en escena el personaje del Náufrago, un hombre muerto que afirma que no podrá descansar hasta que el Señor de Bellver firme la paz. Así pues, se hace evidente que las «almas en pena» y muertos vivientes de Fuga tienen el cometido de plantear en escena la realidad traumática de la guerra, convirtiéndose en portavoces de la memoria de un pueblo masacrado. En este caso el sentido de la obra reside en el alegato antibelicista, que nace, además, de reflexiones personales de la autora inspiradas por las terribles imágenes vertidas en los medios de comunicación en torno al desarrollo de las guerras de los Balcanes, en aquel momento aún activas: «En el verano de 1993 me acompañaron las siluetas del horror. Las voces de mujeres agredidas por la barbarie, las imágenes de la naturaleza abatida por la eficaz naturaleza humana, se mezclaban con reflexiones más íntimas...» (Galindo, 1995: 81). Localizar la acción en un espacio imaginario permite a la autora tratar con mayor libertad el tema de la guerra, sin hacer alusiones concretas al conflicto que tanto impacto estaba causando en la conciencia colectiva. ${ }^{7}$ No es extraño, pues, que aquellas «siluetas del horror» se transformen en la obra en personajes casi fantasmales, que en la puesta en escena de Guillermo Womutt fueron caracterizados con vestimentas ajadas de tonos fríos y envueltos en un ambiente trágico basado en la luminotecnia y el sonido: «Tiene algo de fantasmagórico el espacio escénico. Quienes lo habitan están sumergidos en una densa niebla [...]» (López Mozo, 1995: 24).

El domador de sombras (1994) plantea nuevamente el tema de la memoria, aunque, en este caso, se trata de rendir homenaje a un ámbito muy específico de esta: la cultura del circo. En la obra se evoca un tiempo pasado en el que las compañías circenses viajaban ofreciendo entretenimiento para todos los públicos y los acróbatas y payasos gozaban de gran fama y popularidad. Los personajes de El domador de sombras se enfrentan a la pérdida del interés del público por el circo, desplazado por el desarrollo de la televisión y los nuevos medios de comunicación. La trama transcurre en la actualidad, cuando la oportunidad de revivificar el circo parece perdida, a pesar de los intentos ilusionados de algunos de sus integrantes por devolverle su espacio.

Los protagonistas del drama son dos antitéticos seres venidos del más allá: el payaso Grock, un muerto viviente que se suicidó hace décadas, agobia-

7 Para un estudio sobre las guerras de los Balcanes en el teatro español contemporáneo de autoría femenina, véase García-Manso (2014). 
do por las deudas del circo, y el Espectro del payaso Grock, su pesimista compañero. Grock regresa a los escenarios para recordar las viejas glorias de su profesión y apoyar la supervivencia de un circo que «subsiste todavía con esfuerzos extremos» (5), abandonado por su director y a un paso de la desintegración. El Espectro sirve de contrapunto de la personalidad optimista de Grock, pues le recuerda constantemente la realidad de su muerte y del fracaso del circo. Los otros personajes, vivos todos ellos, representan la decadencia actual del circo y viven sus personales dilemas identitarios, cuya resolución será impulsada por la intervención de Grock. ${ }^{8}$ La Mujer Barbuda, que deseaba abandonar el circo en busca del amor, recupera la ilusión por el circo ante la idea de convertirse en payaso. El Acróbata, que se nos presenta como un artista fracasado y alcohólico, es conminado a mantenerse sobrio para poder enfrentarse con éxito a su último redoble. La Red, a pesar de estar cansada de ser el apoyo invisible del Acróbata, le dará un voto de confianza. Detrás de estas evoluciones individuales se hallan los consejos y ánimos del payaso Grock, quien, a su vez, ha de enfrentarse a una dura realidad: su nombre ha sido olvidado por los jóvenes de hoy.

Grock y su Espectro aparecen caracterizados de manera similar, con «casquete de fieltro gris; maquillaje blanco de la nariz a la barbilla, perfilado en negro; párpados y labios negros; abultado chaquetón a cuadros; botas del número 52; enorme maleta marrón de cartón» (5), si bien el Espectro viste ropas de colores «más opacos, como carcomidos por el tiempo» (4). De la caracterización de estos personajes, interesa su correspondencia con el estilo de la vestimenta de su homónimo histórico, el artista circense Adrien Wettach (1880-1959), alias Grock, el payaso. No obstante, la vida del Grock histórico no tuvo el trágico final del suicidio, por lo que la utilización de su nombre y sus atributos implica más una forma de homenaje al mundo del circo, que una recuperación historicista del personaje. En boca de Grock, además, serán mencionadas otras antiguas celebridades del circo internacional, como las trapecistas españolas Pinito del Oro y Miss Mara o los payasos Giuseppe Grimaldi y Charlie Rivel. La presencia en esta obra dramática de un fantasma -el Espectro del payaso Grock- y de un muerto viviente -el payaso Grock- se justifica tanto por su papel de reivin-

8 El payaso Grock es visible para el resto de personajes, pero el Espectro sólo lo es para el propio Grock, que de vez en cuando cuestiona su presencia. Por otra parte, al payaso Grock no le gusta reconocer que está en realidad muerto, aunque llega a declararlo ante otro personaje, ante la incredulidad de este: «RED: ¿Nos conocemos? / GROCK: No estoy seguro. Todos parecen haberme borrado de sus recuerdos. Incluso a veces me pregunto si he existido. Pero yo no te he olvidado. / RED: Es imposible. [...] ¿Es una broma de mal gusto? / GROCK: Tal vez no es elegante suicidarme y volver al circo. Pero no es una broma. / RED: ¡Estás muerto!» (Pascual, 1996: 182). 
dicación de las viejas glorias del circo, como por su función terapéutica, dado que su cometido es ayudar al resto de personajes, integrantes del circo, a superar sus crisis existenciales personales, a la vez que intentan salvar el circo de la desaparición.

Otro texto en el que hallamos figuras fantasmales, aunque su desarrollo es menor por el carácter episódico de la obra, es Blue Mountain (Aromas de los últimos días) (1999). La obra se compone de breves escenas independientes entre sí, protagonizadas por variados personajes y situadas en diferentes tiempos y espacios, desde el año 611 hasta la actualidad. El nexo común entre las secuencias es de tipo temático: todas ellas están relacionadas de alguna forma con el café. El título de la obra hace referencia a una variedad de grano procedente de Jamaica que se halla entre los más caros y apreciados del mundo, como se explica en la penúltima escena. En el recorrido temático sobre el café que realiza la autora en esta obra, nos interesa destacar dos escenas en las que participan personajes procedentes del más allá.

La primera de ellas transcurre en Puerto Guzmán, Colombia, en junio de 1997. Clemencia Rodríguez, comunicadora social, experta en Derechos Humanos y observadora de una organización no gubernamental, recibe unos disparos mortales durante unos altercados. Se produce entonces un cambio de luces en escena, que anuncia la creación de una nueva dimensión entre la vida y la muerte, un ambiente propicio para la reflexión y la indagación identitaria. Junto a Clemencia aparece Juan Valdés, un personaje publicitario que es marca y símbolo de los cafeteros colombianos. El encuentro con este peculiar fantasma, fruto de la imaginación de la protagonista moribunda, sirve para introducir una reflexión sobre las «mentiras oficiales» de los medios de comunicación y la necesidad de buscar la verdad: «En mi mundo hay verdades a medias y medias mentiras; símbolos como usted, limpiecitos, blancos, sonrientes, y verdades como esta bandera rota. En mi mundo hay gente que se para y gente que se mueve y avanza. Gente que lee todos los días la verdad oficial en un computador y gente que la busca en el dolor de los otros. Y en su propio dolor. (Pausa). Yo la leía. Hasta que me obstiné» (Pascual, 1999: 167).

La segunda escena que nos interesa destacar está protagonizada por dos personajes históricos y uno anónimo: Gerardo Diego, el Poeta Granadino y el Poeta Joven. El diálogo que mantienen nos permite identificar con facilidad a Federico García Lorca en la figura del Poeta Granadino. La acción transcurre en otoño de 1998, los tres personajes son sombras del más allá, reunidas en torno a Gerardo Diego para convencerlo de que cruce hacia el «otro lado de las cosas» (179). En un diálogo que evidencia la expresividad poética tan fre- 
cuente en la escritura de Pascual, se evocan y homenajean escenarios y personajes representativos de la vanguardia artística del primer tercio del siglo xx: «Vamos a las Cumbres de Urbión a releer a Góngora. O a Granada, que nos espera la música de Don Manuel enredada en los cármenes... Vámonos a Soria, que las aulas saben a frialdad y a los pasos de Antonio... Quiero ver torear a "Gallito" y pasear por Salamanca...» (179). Los personajes aluden también a la celebración del centenario del nacimiento de García Lorca y a su muerte, mencionando las palabras que supuestamente sellaron su sentencia -«Dadle café»-, que sirven de enlace con el tema principal de la obra.

También hallamos un fantasma de la Historia en La paz del crepúsculo (2003), obra que forma parte del teatro de denuncia antibelicista tan presente en la trayectoria de Itziar Pascual desde los primeros textos, como Fuga (1994). En esta ocasión la autora plantea una reflexión acerca del dolor que generan las guerras y del sinsentido de todo enfrentamiento bélico, presentada a través de la mirada de las principales armas destructoras de las que se sirven sus artífices: los soldados. La conciencia del soldado, reflejada en el personaje de Dombodán y la Sombra de Clark Gable, ${ }^{9}$ permite revelar la perversión de los ideales en el contexto bélico, convertidos en espejismos para los combatientes.

A diferencia de lo que ocurre en otros textos de la autora, la acción dramática se sitúa en unas coordenadas espaciotemporales precisas, durante la invasión nazi de la Unión Soviética en la II Guerra Mundial, entre el 22 de junio de 1941, fecha en que se produce el inicio de la ofensiva militar, y el 15 de enero de 1942, día de la muerte de la actriz hollywoodiense Carole Lombard, esposa del también actor Clark Gable (Pascual, 2003a: 21). A pesar de que el tiempo acotado en la didascalia es de varios meses, la acción transcurre en tan sólo unos días. No obstante, la acción también tiene lugar «en la imaginación alucinada de Dombodán, provocada por un proceso hipotérmico» (21), es decir, que la acción se nos presenta a través de la percepción de un enfermo, lo que le brinda a la autora la posibilidad de introducir al protagonista en un espacio simbólico, más allá de lo real.

El drama se compone de veintiuna escenas protagonizadas por Dombodán, soldado español de la División Azul, y la Sombra de Clark Gable, que dice haberse separado de su cuerpo en busca de historias. A lo largo de la obra, se irá describiendo el deterioro de la salud del protagonista, víctima de una hipotermia. Dombodán le explica a la Sombra que se alistó como volun-

9 Las referencias al mundo del cine son frecuentes en la obra de Itziar Pascual, además de ser el tema principal de Cineforum y Una noche de lluvia (Zatlin, 2000). 
tario para intentar rebajar la condena de su padre, que está en la cárcel por no haber querido renunciar a sus ideales anarquistas, un aspecto que Dombodán critica y que le lleva a mostrar una actitud desengañada ante la guerra y el fracaso de los idealismos:

LA SOMBRA DE CLARK GABLE: ¿Y las ideas? Usted está apoyando a los fascistas. ¿Qué hace un buen hombre entre fascistas?

DOMBODÁN: (Alterado). No me hable de idealismos. He visto llorar a mi madre por idealismo, no dormir durante semanas por idealismo, quemar libros y documentos por idealismo, negar que conocía a mi padre por idealismo, arrodillarse y limpiar escaleras por idealismo, gritar consignas que no creía por idealismo, engañar al hambre por idealismo, y criarme sola por idealismo... La mayoría huimos o nos obligan. El bando... ¿Cree que lo elegimos? Las ideas son un invento de los que mandan. (Pascual, 2003a: 36)

La Sombra actúa como conciencia de Dombodán y, con el fin de que este supere su traumática memoria personal, le regala un lápiz y un cuaderno con los que dejar testimonio de su experiencia o, al menos, lograr evadirse de la realidad: «Tiene que contar lo que ha vivido, porque si no lo cuenta, nadie lo sabrá, se borrará, se olvidará, no habrá servido de nada. O escriba para salir de aquí, para escaparse, para resistir, para no pensar» (54). Dombodán es, al principio, un hombre que no quiere recordar y enfrentarse a sus sentimientos. La llegada del espectro despierta en él la necesidad de revisar su conciencia, de cuestionarse la relación con su padre, el valor de la esperanza y los ideales y de reinterpretar su memoria personal y colectiva. Tal y como señala Zachman, esta reflexión se extiende a la conciencia colectiva del público, al que se reta «a no olvidar ni huir; a recordar para no repetir, a contar y escuchar historias propias; a enfrentarse con y aprender de los fantasmas de la historia; a no perder la esperanza; y, por fin, a seguir creyendo y escribiendo» (2003: 16).

En la escena final de la obra se constata que el protagonista estaba siendo atendido por un médico que le recuerda a Clark Gable y a quien se dirige, en medio de sus alucinaciones, de la misma manera en la que se dirigió a la Sombra durante su primer encuentro. No obstante, el propio médico introduce la duda sobre la posibilidad de que el enfermo pueda ver más allá de lo visible $^{10}$ y Dombodán, como prueba del encuentro con la Sombra, guarda en

10 «Vienen desquiciados del frente ruso. Dios sabrá lo que habrán tenido que padecer. (Se quita las gafas, cansado). Aunque... Tal vez ellos ven lo que nosotros no vemos. ¿Qué sabemos de lo visible y de lo invisible?» (Pascual, 2003a: 80). 
sus manos el lápiz que éste le dio. En este caso podemos hablar de lo fantástico, pues las fronteras entre lo real y lo insólito no están claras.

El texto dramático de Père Lachaise (2003) está dividido en dos actos precedidos de una «Obertura» en la que, «mientras el público accede a la sala», se proyectan imágenes de obras pictóricas en el ciclorama, pertenecientes a diversos artistas del siglo xx que encontraron en París su inspiración artística. La acción transcurre en «una velada calurosa de agosto de 2002», entre el mediodía y el atardecer, en el cementerio de Père Lachaise, conocido y visitado por contener las tumbas de escritores, artistas y otros personajes célebres. En una entrevista la autora comenta que Père Lachaise ha sido escenario de «homenajes a las víctimas del nazismo, del holocausto, a los españoles republicanos que lucharon en defensa de la ciudad de París» (García Salch, 2006). Según observa John P. Gabriele en su estudio sobre esta obra, los cementerios son lugares liminales que se prestan a la negociación y la construcción identitaria: «Those who have studied the metaphorical significance of cemeteries have demonstrated that they symbolize "liminal places" that "bridge notions of self and other, time and space", that they are "places where geography and chronology are reshape and history is spatially spread out", and therefore constitute appropriate localities for focusing on "negotiations of identity formation and [...] construction"» (2006: 166). ${ }^{11}$

En la obra participan seis personajes, tres de ellos fantasmas del cementerio parisino, a los que se suman, en la descripción de los dramatis personae, una serie de «espíritus, sombras y seres de inframundo» que han de manifestarse en momentos concretos de la trama. Los personajes del drama asisten, en el espacio histórico e historiado de Père Lachaise, a una negociación de su propia identidad, la cual entra en conflicto con la memoria de un pasado opresivo. Carlota y Cundo, los protagonistas, son dos hermanos que viajan a París por iniciativa del primero, que quiere visitar la tumba de su abuelo, un combatiente republicano que se exilió tras el final de la Guerra Civil y «se dejó la vida por la libertad» de Francia (13). Carlota lo acompaña porque necesita huir de una relación amorosa que no le deja avanzar. En el cementerio de Père Lachaise se encuentran con Michel, un sepulturero hijo de una emigrante española, ${ }_{1}^{12}$ que vive acechado por un sentimiento de culpa

11 Las palabras entrecomilladas aparecen identificadas por Gabriele como procedentes del ensayo «The Cemetery. A Site for the Construction of Memory, Identity, and Ethnicity», de Doris Francis, Leonie Kellaher y Georgina Neophytou, publicado en Social Memory and History. Anthropological Perspectives (2002).

12 La alusión a la emigración española de los años 60-80 completa así el cuadro de los flujos migratorios de españoles hacia el exterior del siglo XX. Cuando Michel le cuenta a Cundo que su 
consecuente de la muerte de su mujer en un accidente de coche. Michel les previene de las leyendas que circulan sobre el cementerio, avisándoles de que «es fácil perder la identidad en Père Lachaise», porque los espíritus «se apropian por unas horas de los cuerpos» de los visitantes «para encontrar su camino de ascensión» y «desprenderse de una muerte dolorosa o inesperada» (17). Efectivamente, los tres personajes vivos padecen transformaciones repentinas, manifestadas a través de «gestos espasmódicos» y una particular «coreografía de una revelación» (16), encarnando temporalmente a los fantasmas de tres muertos: el cuerpo de Cundo es «poseído» por el del espíritu de Secundino, el de Michel por el del Ilustre Anónimo y el de Carlota por el de Isadora Duncan.

Los tres espíritus conservan, como los vivos, «recuerdos traumáticos y sensaciones de culpabilidad» (Harris, 2003: 10) que les han impedido «ascender» y les mantienen atados al mundo de los vivos. Secundino Pérez, que no es otro que el abuelo de Cundo y Carlota, no consigue olvidar su deuda con sus correligionarios españoles, cuyos cadáveres fueron enterrados en fosas comunes. Isadora Duncan, bailarina y coreógrafa estadounidense, soporta asimismo el trauma de la muerte trágica de sus dos hijos, mientras que el Ilustre Anónimo no ha alcanzado la paz porque no supo en vida seguir su propio camino e hizo de sí mismo lo que su padre quiso de él. La presencia de espectros en el escenario permite conectar la experiencia de los vivos con la de los muertos y rescatar del olvido aquellos recuerdos sin los que la esencia del individuo, y por extensión, la de la sociedad, quedaría incompleta. En palabras de Carolyn J. Harris, «los espíritus de Père Lachaise se relacionan con la memoria, trayendo a los vivos que les escuchan lo que Pascual ha llamado 'un depósito de memoria y de conciencia' que les falta. [...] La presencia de los muertos y sus recuerdos en la dramaturgia española actual representa para Pascual no sólo una opción teatral sino "una reflexión profundamente ética"'» (2003: 11).

Al final de la obra, todos los personajes consiguen redirigir sus vidas -y sus muertes- tras asimilar sus errores y traumas del pasado. Su búsqueda identitaria culmina así con un reconocimiento de la memoria individual que, en algunos casos, como el de Secundino, forma parte de la memoria colectiva, en lo que respecta a su experiencia como combatiente de la guerra civil española, el exilio, la II Guerra Mundial y la vindicación de exhumar los cuerpos

madre emigró a Francia "para trabajar», Cundo afirma, significativamente: «la emigración también es una cuestión política» (Pascual, 2003b: 13). 
de las fosas comunes del franquismo. ${ }^{13}$ Así pues, Cundo terminará por encontrar la tumba del abuelo en Père Lachaise, ante la cual se promete a sí mismo no olvidarlo ni a él ni a sus ideas. Carlota, por su parte, descubrirá que está embarazada y tomará la decisión de rehacer su vida de forma independiente. Michel decide dejar de esconderse y se ofrece para ser el guía turístico de Carlota en París. Secundino, por su parte, cede a la generación de sus nietos la responsabilidad de dar una sepultura digna a sus compañeros. Isadora Duncan decide asimilar la muerte de sus hijos y dejarles descansar. Y el Ilustre Anónimo abandona su obstinación y se perdona a sí mismo por no haber seguido su propio camino.

En Mascando ortigas (2005) asistimos a un caso de reconstrucción de la identidad individual. La protagonista de la obra, Pina Mujer, se enfrenta a su pasado con la ayuda de un fantasma de la memoria, representado por su yo-infantil, la niña que fue cuando tenía siete años. Pina Mujer y Pina Niña llevarán a cabo un viaje introspectivo de indagación identitaria, para el cual será necesario que la mujer adulta asuma un pasado torpemente relegado al olvido, que aparece simbólicamente representado por la casa y el restaurante que fue propiedad de sus padres, hogar de la memoria familiar al que regresa con el fin de venderlo. ${ }^{14}$ La irrupción de Pina Niña motivará un cambio en la actitud vital de la adulta.

A lo largo de las siete escenas que componen la obra se le van desvelando al público las reflexiones y recuerdos de Pina, una mujer introvertida que tuvo una infancia difícil y que se ha acostumbrado a evitar los problemas y a refugiarse en el trabajo. El contacto con la casa familiar despierta en su memoria recuerdos deliberadamente olvidados, como la muerte de los padres y la búsqueda de consuelo en su trabajo de bailarina, que antepondrá a su propia salud. La anagnórisis termina siendo beneficiosa para la protagonista, ya que le permite superar viejos temores y retomar su vida

13 «EL ILUSTRE ANÓNIMO. ¿Por qué te aferras a seguir aquí? / SECUNDINO: No es por mí. (Pausa). Es por los compañeros. Siguen allí, junto al castañar. Allí los fusilaron. Amasijo de huesos sin nombre. Ni siquiera una tumba. / EL ILUSTRE ANÓNIMO: ¿Qué puedes hacer por ellos? / SECUNDINO: Yo fui el único que sobrevivió. Conseguí huir. Después la frontera, Francia, el exilio. Después los nazis. Yo sé dónde están. Si yo les olvido nunca les encontrarán. Los vivos olvidan con facilidad. Ya nadie se acuerda de la guerra» (Pascual, 2003b: 22).

14 También en BILBAO: Lauaxeta, tiros y besos (2002), de Maite Agirre, los fantasmas del pasado aparecen en un entorno familiar, un viejo bar, al que regresa la protagonista antes de que se produzca su demolición. Allí, la protagonista y el público asisten a una revivificación sobre la escena de sus memorias personales de juventud, que forman parte de la intrahistoria de la guerra civil española. El restaurante de los padres de Pina es identificado en la obra con la memoria y la infancia de la protagonista, como declara el «fantasma» de Pina Niña: «Si vendes este restaurante me vendes a mí. Y a Jean. Y a la señora Martine. Y a todos. Todos estamos dentro. Incluidos papá y mamá» (Pascual, 2005d: 46). 
con mayor seguridad e ilusión. En este proceso de reafirmación identitaria, la asimilación del pasado resulta crucial. La casa familiar abandonada y el restaurante se convierten en espacios simbólicos y liminales, en los que se unen pasado y presente, espacios en los que la protagonista reconsidera su identidad y se desnuda física y espiritualmente, como se observa en este fragmento:

PINA MUJER: (Se va desvistiendo, lentamente. Al público.)

Volver a casa. El espacio viejo, antiguo del pasado.

Volver para vaciar la materia, para hacerla liviana.

Volver para cerrar con llave las heridas de entonces.

(Descalza y con el vestuario de la escena 1.)

¿Cuándo empezó la fragilidad? ¿Cómo? No sé.

Me asustaba lo que pudiera pasar, cualquier cosa. [...]

Puede que no fuera quien soy sin aquel restaurante. (Pascual, 2005d: 44)

Pina Niña, la proyección infantil de la protagonista, aparece en estos espacios de la memoria para cumplir la misma función que los fantasmas del resto de obras comentadas: ser portavoz de la historia de la protagonista y actuar como contrapunto de su personalidad y desencadenante del proceso de reconstrucción identitaria. El mecanismo utilizado -la indagación en la memoria personal y la asimilación de los traumas del pasado, que facilitan la anagnórisis del personaje principal- es similar al de las otras piezas, si bien, en este caso, se trata de la identidad individual de una mujer concreta, en la que el público juvenil e infantil al que se dirige la obra puede verse reflejado: la protagonista y su yo-infantil representan la necesidad que el ser humano tiene de reconocerse como individuo, asumir y hacer justicia a su pasado y evitar, como señala Pina, la temeridad de las huidas hacia el futuro. Una función equivalente a la que desempeñan los fantasmas de la memoria histórica en su indagación sobre la identidad colectiva.

El fantasma de Despedida (2005), por su parte, guarda relación tanto con la memoria individual de los personajes de la obra, como con la memoria colectiva del público, al estar sus experiencias estrechamente ligadas a un pasado histórico. El texto dramático se divide dos escenas, con obertura y epílogo, y está protagonizado íntegramente por mujeres, a través de las cuales se plantean temas como la maternidad, la salud reproductiva, la conciliación de la vida personal, familiar y laboral o el cuidado de familiares dependientes. Las preocupaciones y problemas de las protagonistas se plantean y resuelven desde la perspectiva de la sororidad -el apoyo mutuo entre mujeres- y la comu- 
nicación intergeneracional, pues aparecen representadas tres generaciones sucesivas de mujeres.

El fantasma de Despedida es Mónica, una mujer joven que falleció durante la Guerra Civil tras perder a su hija. Su amiga María, que se hace presente en la obra a través de las alusiones del resto de personajes, la envía desde el más allá para que vea a sus nietas y las ayude a convertirse en «dos mujeres de provecho» (Pascual, 2005a: 216). María era anarquista y su marido fue represaliado en la guerra, por lo que tuvo que exiliarse en Francia, donde crió a su hija. Sus nietas son Marina y Águeda, mujeres adultas que están en el hospital de visita para ver a su madre enferma. La primera está casada y tiene hijos, trabaja en una empresa y carece de tiempo para cuidar de sí misma o visitar con tranquilidad a su madre enferma. La segunda está soltera y escribe una tesis sobre Frida Kahlo, trabaja en condiciones precarias y ha de enfrentarse a un embarazo inesperado. El encuentro de las dos hermanas es tenso, ya que tienen problemas personales y rencores que se guardan para sí. No obstante, a través del diálogo y con la «inspiración» de Mónica, siempre presente, irán desvelando sus preocupaciones y estableciendo una complicidad mutua y sincera, que les ayudará, como ocurría en Mascando ortigas, a indagar en su identidad y avanzar para intentar ser mujeres «felices y sanas» (Pascual, 2005a: 242-3). Al mismo tiempo, las alusiones a las vidas de Mónica y María, la generación ya desaparecida, le permiten al público considerar una parte de la intrahistoria de la Guerra Civil y el exilio republicano de 1939 y profundizar en la memoria colectiva de aquellos hechos.

El fantasma de Mónica, a diferencia de otras sombras y espectros ya comentados, no interactúa de forma directa con las protagonistas. Permanece como observadora de la evolución de los personajes, que comenta y matiza, dando a menudo información sobre su propia vida y los problemas a los que tuvo que enfrentarse, estableciéndose así una relación entre la condición femenina actual y la de principios del siglo xx. En este sentido, puede ser considerada también una ayudante para el desarrollo de la acción, pues, aunque no intervenga en ella, lanza preguntas y observaciones a las protagonistas que serán contestadas cuando ellas manifiesten a viva voz sus reflexiones. El único personaje que se dirige directamente a Mónica es la madre, que nunca vemos en escena pero que escuchamos a través de una voz en off. La madre, enferma y hospitalizada, es la única capacitada aquí para intuir la presencia de Mónica y hablarle. Su estado febril le permite conectar con ese mundo de lo intangible, como ocurría en La paz del crepúsculo con Dombodán. De esta ma- 
nera, se establece una comunicación a distintos planos, por una parte, los diálogos entre las hermanas, por otra, la expresión monologal de sus reflexiones internas, y, por otra, los comentarios o apartes del fantasma y la voz en off de la madre enferma, que se manifiesta únicamente en la obertura y el epílogo de la obra.

La última obra que recogemos en este estudio, Variaciones sobre Rosa Parks (2008), trata sobre la situación de discriminación a la que están sometidas las mujeres no sólo en su vida cotidiana sino también en los discursos historiográficos y culturales, que modulan nuestra manera de ver y entender la realidad. La protagonista, Rosa Parks (1913-2005), fue una figura emblemática del movimiento por los derechos civiles en los Estados Unidos. La obra gira en torno a la memoria del suceso que hizo célebre a esta costurera de Montgomery, quien, en diciembre de 1955, se negó a ceder su asiento a un hombre blanco en un autobús segregado, motivo por el cual fue arrestada. En respuesta a su detención se llevó a cabo un boicot contra el transporte público que duró 381 días, durante el cual cientos de trabajadores negros fueron despedidos y muchos arrestados, como la propia Parks. Este acontecimiento es considerado el comienzo de la lucha política y social en contra de las leyes segregacionistas en Estados Unidos. ${ }^{15}$

Itziar Pascual realiza en esta obra un acercamiento a la protagonista histórica en su ancianidad, desde la perspectiva de la memoria. Al igual que en otras obras que ya hemos comentado, como La paz del crepúsculo o Despedida, en las que los anónimos protagonistas indagaban en su memoria individual y colectiva, la Rosa Parks de Variaciones se enfrenta a sus recuerdos tamizados por los efectos de la demencia senil, que le han agriado el carácter, además de provocarle un desdoblamiento de personalidad. La protagonista se presenta física y psicológicamente dividida en dos personajes -e intérpretes-, un recurso teatral que permite confrontar al personaje histórico con la reflexión sobre su pasado y lo que supuso su gesto en el bus de Montgomery. ${ }^{16}$ Desde el comienzo de la acción, la protagonista confiesa que olvida los hechos recientes, pero no los del pasado. Como explica Itziar Pas-

15 La obra contiene numerosas referencias e intertextos de carácter histórico y cultural cuyo análisis ofrece Phyllis Zatlin en su estudio (2000).

16 A pesar de que la Sombra de Rosa Parks no es un fantasma al uso (la protagonista histórica está viva en el momento en que transcurre la acción y la Sombra se presenta como un desdoblamiento físico de su conciencia), su función escénica es similar a la de los fantasmas de la memoria que hemos visto: ayudar a la protagonista -y con ella, al público- a indagar sobre un suceso histórico pasado, sirviéndose para ello de un discurso metamnemónico. En mi opinión, podemos considerar su presencia como una intromisión de lo maravilloso en la escena, dado que su aparición en el contexto de lo real se plantea ante el público de manera naturalizada. 
cual en el siguiente fragmento, la creación de este doble personaje responde a una intencionalidad metamnemónica y de reflexión sobre la fijación de la Historia:

He querido acercarme a Rosa Parks y preguntarme con ella cómo y quién escribe la Historia. Las circunstancias de los últimos años -Rosa padeció de demencia senil- me permitían compartir con el personaje estas preguntas. Permitirnos un acercamiento a la Rosa que se atrevió y a la Rosa que tenía miedo, a la que quiere recordar y a la que ha olvidado, a la que cree que el cambio es posible y a la que sabe que no hay acceso libre a la libertad. Freedom is not free. (Hartwig y Pörtl, 2008: 30)

Así pues, la autora propone representar en su obra dos modalidades diferentes y enfrentadas de la personalidad de Rosa Parks, que funcionan como las dos caras de la misma moneda: por un lado, la Rosa Parks que se cansó y decidió no ceder su asiento, y, por otro, su alter ego, la Sombra de Rosa Parks, que evita el conflicto y aboga por el olvido y la resignación. El personaje de la Sombra funciona nuevamente como contrapunto dramático de la protagonista, introduciendo la duda y cuestionando las reflexiones del personaje de Rosa Parks.

La obra se compone de ocho escenas que están pensadas para ser interpretadas por dos actrices, en los papeles de Rosa Parks y su Sombra. Se alude a otros personajes, pero su presencia no es necesaria en escena: Rhea, la sobrina de Rosa Parks, con la que habla por teléfono en la primera escena y los periodistas que acuden a entrevistar a Rosa, de cuya conversación sólo oímos la parte que atañe a la protagonista. La acción dramática presenta una estructura lineal, aunque fragmentaria y con frecuentes flashbacks a la biografía de la protagonista. En la primera escena Rosa Parks habla por teléfono con Rhea para pedirle que le traiga una grabadora, ya que quiere ordenar sus recuerdos. A partir de entonces, se dedica a rememorar algunos momentos del pasado, empezando por un recuerdo de la infancia, en el que le pregunta a su madre «de qué color es Dios» (Pascual, 2008: 37), y continuando por el día en que decidió no levantarse de su asiento en el autobús. En la escena 3, la autora establece una analogía entre el sencillo, pero influyente gesto de rebelión de Rosa Parks y el mito de Antígona. ${ }^{17}$ Rosa Parks y su Sombra se sitúan, cada cual, al lado de una de

17 Antígona es uno de los personajes míticos grecolatinos más recurrentes del teatro español contemporáneo. Como señala Francisca Vilches-de Frutos en su estudio sobre La sangre de Antígona, de José Bergamín, y La tumba de Antígona, de María Zambrano, su presencia es «una llamada de atención 
las dos hermanas -Antígona e Ismene-, trazando un paralelismo entre sus diferentes formas de ver la realidad: mientras que una aboga por la oposición a la ley injusta, la otra prefiere salvaguardar su integridad personal situándose dentro de los márgenes impuestos:

ROSA PARKS: Siempre las acciones son más grandes que nosotros. No puedo. Es demasiado para mí. No sé. Los que mandan, mandan. ¿Y entonces? Todo queda igual. Mira lo que dice el libro: «No le compete en absoluto al poder separarme de lo que es mío».

LA SOMBRA DE ROSA PARKS: ¿Cómo termina el libro? Dime cómo termina Antígona.

ROSA PARKS: Antígona muere.

[...] LA SOMBRA DE ROSA PARKS: ¿Quieres que tu vida sea una tragedia? Ismene, la que acepta los límites, sigue viva.

ROSA PARKS: Lo que no dice Sófocles es cómo.

LA SOMBRA DE ROSA PARKS: ¿Qué quieres decir?

ROSA PARKS: Como vivió Ismene tras perder a todos sus hermanos. Los dos primeros, Eteocles y Polinices, muertos en batalla y Antígona, muerta en la cueva en la que estaba encerrada. Antes había perdido a su madre. ¿Cómo se vive con eso? ¿Perder a los tuyos, perder tus derechos y no hacer nada? ¿Cómo se sale de esta cárcel? ¿Bajando la cabeza? ¿Una vez más? (Pascual, 2008: 56-8)

La actuación de los arquetipos míticos de Antígona e Ismene se relaciona, a su vez, con las dos maneras de encarar la injusticia - una más combativa, otra más resignada- que se contraponen en la obra. Rosa Parks, en diálogo constante con su Sombra, revive otros momentos relevantes de su vida, como el tiempo que pasó en prisión o su éxodo de Montgomery a Detroit. La escena 5 se dedica íntegramente a dicho exilio que emprende la protagonista con el fin de rehacer su vida: «Destino a Detroit, lejos del miedo, lejos del 'no hay trabajo para ti, para ti no'. / Lejos de los días agrios, de las victorias que duelen, de las noches de gritos. / Necesito ser Rosa, una mujer más, una costurera, sin cargar con tanto» (69). Las dos últimas escenas, por su parte, regresan al presente de la acción, en el que Rosa y su Sombra -pues cada una de las escenas se produce desde la perspectiva de una de ellas- son entrevistadas por unos periodistas.

Como hemos visto en este recorrido por la obra de Itziar Pascual, la creación de espectros en el teatro español contemporáneo se relaciona a me-

a la sociedad para poner en marcha todas aquellas acciones que permitan recuperar la memoria y la historia de un país» (2006: 93). 
nudo con la necesidad de representar un pasado conflictivo, sobre el que pesa una pátina de olvido que se pretende retirar con el fin de plantear una reflexión contemporánea en torno a cuestiones de acuciante actualidad. El personaje fantasmagórico se convierte en estas obras en metáfora o corporeización de la memoria en la medida en que brinda la posibilidad de materializar el discurso mnemónico sobre la escena. Normalmente, se trata de fantasmas que no persiguen a los vivos para hacerles recordar, sino que, más bien, son los vivos quienes los buscan, guiándose a través de ellos para indagar en su memoria personal, familiar o colectiva, reconstruyendo así sus vínculos identitarios. Esta intromisión de seres sobrenaturales en escenarios de ambientación realista y objetivista permite dar forma a la ilusión teatral de la presencialidad del pasado en el presente. Tanto si los temas planteados pertenecen a la memoria colectiva, como si son fruto de una experiencia individual, la función de estos personajes espectrales consiste en dar cuerpo a la memoria del pasado, en traerla a colación en el presente con el fin de resolver viejos traumas y lograr así llevar a cabo la reconstrucción identitaria.

\section{BIBLIOGRAFÍA}

AdHAM, Leila (2008): «Mémoire et poétique de la spectralité. Le fantôme comme figure de lutte contre l'oubli», en C. Hähnel-Mesnard, M. Liétard-Yétérian y C. Marinas, Culture et mémoire. Représentations contemporaines de la mémoire dans les espaces mémoriels, les arts du visuel, la littérature et le théâtre, Éditions de l'École Polytechnique, Paris, pp. 475-82.

Colmeiro, José (2011): «A Nation of Ghosts? Haunting, Historical Memory and Forgetting in Post-Franco Spain», $425^{\circ}$ F. Electronic Journal of Theory of Literature and Comparative Literature, 4, pp. 17-34, disponible en http://www.452f.com/pdf/ numero04/colmeiro/04_452f_mono_colmeiro_indiv.pdf [06-05-2014].

DerridA, Jacques (1993): Spectres de Marx : l'état de la dette, le travail du deuil et la nouvelle internationale, Galilée, París.

De BeNI, Matteo (2012): Lo fantástico en escena. Formas de lo imposible en el teatro español contemporáneo, Academia del Hispanismo, Vigo.

GABriele, John P. (2006): «Plotting Postmodern Being in Itziar Pascual's Père Lachaise», Studia Neophilologica, 78.2, pp. 165-75.

< http://dx.doi.org/10.1080/00393270601020831 >

Galindo, Carlos (1995): «Fuga desembarca en el C. C. Galileo», ABC, 6 diciembre, p. 81.

GARcía-MANSo, Luisa (2011): «Teatro, inmigración y género: la identidad del Otro en Víctor Bevch, de Laila Ripoll, e Y los peces salieron a combatir contra los hombres, de Angélica Liddell», Anales de la Literatura Española Contemporánea, 36.2, pp. 113-49. 
(2013): Género, identidad y drama histórico escrito por mujeres en España (1975-2010), Oviedo, KRK.

(2014): «Las guerras de la Ex Yugoslavia en la creación dramática femenina española», Revista de Escritoras Ibéricas, 2.

García Salch, Alberto (2006): «Entrevista con Itziar Pascual: Me considero contemporánea porque abordo temas no resueltos por la cultura», en Parnaseo, disponible en http://parnaseo.uv.es/ars/autores/pascual/autor/lachaise/resenya4. jpg [03-11-2014].

GuzMán, Alison (2012): «Los muertos vivientes de la Guerra Civil en cinco obras de Laila Ripoll: La frontera, Que nos quiten lo bailao, El convoy de los 927, Los niños perdidos, y Santa Perpetua», Don Galán. Revista de Investigación Teatral, 2, disponible en http://teatro.es/contenidos/donGalan/donGalanNum2/pagina.php?vol=2\&doc $=2 \_4$ [03-11-2014].

HARris, Carolyn J. (2003): «Memoria, conciencia y danza en Père Lachaise», en Itziar Pascual, Père Lachaise, Asociación de Autores de Teatro / Consejería de las Artes de la Comunidad de Madrid, Madrid, pp. 9-14.

Hartwig, Susanne y Klaus Pörtl (2008): La voz de los dramaturgos. El teatro español y latinoamericano actual, Niemeyer, Tübingen.

LABANYI, Jo (2000): «History and Hauntology; or, What Does One Do with the Ghosts of the Past? Reflections on Spanish Film and Fiction of the Post-Franco Period», en Joan Ramon Resina (ed.), Disremembering the Dictatorship. The Politics of Memory in the Spanish Transition to Democracy, Amsterdam, Rodopi, pp. 65-82.

López Mozo, Jerónimo (1995): «Fuga. Poesía dramática», Reseña, 269 (1995), p. 24.

Muro Munilla, Miguel Ángel (2012): «El teatro de Maite Agirre: la fiesta de confabulación con el público», Signa, 21, pp. 85-113.

Nieva-de la Paz, Pilar (1999): «Y María tres veces amapola María (1998), de Maite Agirre: una visión del testimonio histórico y existencial de María de la O Lejárraga (1874-1974)», en José Romera Castillo y Francisco Gutiérrez Carbajo (ed.), Teatro histórico (1975-1998). Textos y representaciones, Visor, Madrid, pp. 399-408.

Pascual, Itziar (1994): Fuga, en Itziar Pascual, Encarna de las Heras, Sara Molina y Liliana Costa, Fuga / La orilla rica / El último gallo de Atlanta / El sello de la necesidad, Nuevo Teatro Español, 15, Ministerio de Cultura, Madrid, pp. 11-26.

(1996): El domador de sombras, en Candyce Leonard y John P. Gabriele, ed. Panorámica del teatro español actual, Fundamentos, Madrid, pp. 167-94.

(1999): Blue Mountain (Aromas de los últimos días), en Carol López Díaz, Victoria Szpunberg Witt e Itziar Pascual, Susie / Entre aquí y allá / Blue Mountain, «Premio María Teresa León, 1998», 23, ADE, Madrid, pp. 147-93.

(2002): «Un esbozo de ideario dramático», La Ratonera. Revista Asturiana de Teatro, 4, (enero 2002), pp. 102-05.

(2003a): La paz del crepúsculo, en Itziar Pascual, Tomás Afán, Alberto Iglesias, La paz del crepúsculo / Parejas / Me la maravillaría yo, III Premio de Teatro Serantes, Ayuntamiento de Santurtzi, Bilbao, pp. 7-81.

(2003b): Père Lachaise, Asociación de Autores de Teatro, Madrid. 
(2005a): Despedida, en Manuel Lorenzo e Itziar Pascual, O glaciar. El glaciar / Voces de mujer. Nana. Despedida, El Teatro de Papel, 2, Primer Acto, Madrid, pp. 201-45. (2005b): «El poder invisible», en Manuel Lorenzo e Itziar Pascual, O glaciar. El glaciar / Voces de mujer. Nana. Despedida, El Teatro de Papel, 2, Primer Acto, Madrid, pp. 149-60.

(2005c): Fuga, en CELCIT, http://www.celcit.org.ar/bajarArchivo.php?id=200\&$\mathrm{t}=$ publicaciones $\& \mathrm{c}=\mathrm{dla} \& \mathrm{e}=\mathrm{pdf} \& \mathrm{f}=200 . \mathrm{pdf}[03-11-2014]$. (2005d): Mascando ortigas, Asociación Española de Teatro para la Infancia y la Juventud, ASSITEJ España, Madrid.

(2008): Variaciones sobre Rosa Parks, Servicio de Publicaciones Universidad Complutense, Madrid.

Resina, Joan Ramon, ed. (2000): Disremembering the Dictatorship. The Politics of Memory in the Spanish Transition to Democracy, Amsterdam, Rodopi.

RoAs, David (2001): «La amenaza de lo fantástico», en David Roas (ed.), Teorías de lo fantástico, Madrid, Arco/Libros, pp. 7-44.

Unamuno, Miguel de (1972): En torno al casticismo [1905], Espasa-Calpe, Madrid.

VilcheS-DE Frutos, Francisca (2006): «Mitos y exilios en la construcción de la identidad colectiva: Antígona en el teatro español contemporáneo», Hispanística XX, 24, pp. 71-93.

Zachman, Jennifer A. (2003): «Prólogo. Las sombras de la historia y el poder de la memoria», en Itziar Pascual, Tomás Afán y Alberto Iglesias, La paz del crepúsculo / Parejas / Me la maravillaría yo, III Premio de Teatro Serantes, Ayuntamiento de Santurtzi, Bilbao, pp. 11-16.

Zatuin, Phyllis (2000): «Cine en teatro: Una noche de lluvia, de Itziar Pascual», Acotaciones, 5, pp. 93-102.

(2008): «¿De qué color son los sueños?», en Itziar Pascual, Variaciones sobre Rosa Parks, Madrid, Universidad Complutense, pp. 13-19. 